\title{
Workplace Violence: A Survey of Nationally Registered Emergency Medical Services Professionals
}

\author{
Anthony Oliver ${ }^{1,2}$ and Roger Levine ${ }^{3}$ \\ ${ }^{1}$ Office of Emergency Medical Services, National Highway Traffic Safety Administration, 1200 New Jersey Avenue SE (NTI-140), \\ Washington, DC 20590, USA \\ ${ }^{2}$ Association of Schools and Programs of Public Health, 1900 M Street NW, Suite 710, Washington, DC 20036, USA \\ ${ }^{3}$ Private Practice, 168 Iris Street, Redwood City, CA 94062, USA
}

Correspondence should be addressed to Anthony Oliver; alo2106@columbia.edu

Received 29 August 2014; Revised 19 March 2015; Accepted 29 April 2015

Academic Editor: How-Ran Guo

Copyright (C) 2015 A. Oliver and R. Levine. This is an open access article distributed under the Creative Commons Attribution License, which permits unrestricted use, distribution, and reproduction in any medium, provided the original work is properly cited.

\begin{abstract}
Previous studies on violence against prehospital personnel have mainly reported on "verbal" and "physical" violence. This study explored how provider demographic and work-related characteristics were associated with five different forms of workplace violence (being cursed or threatened; being punched, slapped, or scratched; being spat upon; being stabbed/stabbing attempt; and being shot/shooting attempt). A cohort of nationally registered United States Emergency Medical Services professionals was surveyed to determine the experience of each of these types of patient initiated violence by these providers and their partners. Multivariable logistic regression analyses indicated gender was significantly associated with both being cursed/threatened and being stabbed or experiencing a stabbing attempt (odds ratio $(\mathrm{OR})=0.65, \mathrm{CI}=0.44-0.96 ; \mathrm{OR}=0.27, \mathrm{CI}=0.09-0.75$, resp.). Level of EMT practice was significantly associated with being cursed/threatened, being spat upon, and being punched, slapped, or scratched $(\mathrm{OR}=0.17$, $\mathrm{CI}=0.11-0.27 ; \mathrm{OR}=0.30, \mathrm{CI}=0.21-0.43 ; \mathrm{OR}=0.31, \mathrm{CI}=0.22-0.44$, resp.). Both community size and experience were significantly associated with all the types of violence investigated. EMS workplace violence research is at its infancy; thus this study adds to a limited but growing body of knowledge.
\end{abstract}

\section{Introduction}

The health care sector experiences some of the highest risks of job-related violence [1]. Among employees that require days away from work to recuperate from occupational injuries, health care and social assistance workers experience violence at triple the overall rate for private sector workers [1]. Preliminary investigations of violence in the prehospital setting estimate that some form of violence occurs in 8.5 percent of patient encounters and that providers were subjected to violence directed at them in 4.5 percent of patient encounters [2]. The prehospital environment is unique and unpredictable. Safety measures developed for violence reduction in the Emergency Department (ED) may not translate very well to the prehospital setting, where the environment is unstructured and manpower resources are frequently limited.
The definition of workplace violence utilized by the National Institute for Occupational Safety and Health (as "violent acts, including physical assaults and threats of assault, directed toward persons at work or on duty") means that threats of either physical harm or violence are forms of workplace violence [3]. Although some research into prehospital workplace violence has been conducted, it has mainly focused on determining the prevalence of violence. To date, there is a paucity of research that has explored factors that are associated with an increased risk of exposure to violence. Furthermore, with the exception of one study [4], researchers have tended to group aggression into the larger categories of "verbal" and "physical" violence. The importance of categorizing violence against EMS personnel was highlighted by the American College of Emergency Physicians [5]. In this paper, specific forms of physical (harmful acts that involve physical contact) and nonphysical 
(harmful acts that include verbal abuse and psychological harassment) aggression were categorized.

Previous work has shown that health care workers who reported physical assault were more likely than others to have missed work [6]. Since many physical assault incidents in health care settings do not require treatment [7], this suggests that the subsequent episodes of missed work are only partially due to the direct consequences of physical assault (e.g., the injury inflicted by an attack). Maintaining physical and emotional well-being is essential to the functioning of an emergency service [8]. The finding that the frequency of exposure to abusive and violent situations was among the top three stressors identified by EMS personnel [4] highlights the need for prehospital providers to have access to counseling and psychological services for stress and support. Furthermore, the Occupational Safety and Health Administration recommends the establishment of a comprehensive program of medical and psychological counseling for employees that experience or witness assaults and other violent encounters [9]. Employee assistance programs (EAPs) are important worksite programs which not only address worker general personal welfare [10-12], but also offer a structured mechanism for the provision of short-term counseling to employees facing personal problems such as emotional distress [13], potential sequelae of workplace violence.

Workplace aggression can also impact patients and employers [6]. For example, perceptions of decreased personal safety may adversely affect the ability of staff to care for patients [14]. Preliminary investigations have shown that 84\% of EMS personnel believed that their personal safety was at risk because of violence in the field. Ninety-two percent reported that occurrences of assault have affected their attitude about work [4]. Additionally, exposure to violence may contribute to personnel shortages through increased workforce injury and disability.

There is a lack of information on the experience of workplace violence among EMTs and specifically an absence of studies researching how workplace violence is associated with the demographic and occupational characteristics of prehospital personnel. The body of workplace violence data in some health care settings has led to an understanding of some of the factors responsible for these events and to specific recommendations by professional societies and regulatory agencies to address these problems. While some time has passed since the data were originally collected, we do not believe that the discovered associations have changed greatly, as there has been no major legislation or initiatives implemented since then. There have not been any major shifts in the underlying issues investigated, nor have there been any meaningful changes in policy or practice that would considerably influence the experience of workplace violence in the prehospital setting. Researchers have commented that the problem of prehospital workplace violence is not well documented or researched [15], which was reiterated in a publication distributed by the US National Highway Traffic Safety Administration [16]. To learn more about patient initiated workplace violence, the National Registry of Emergency Medical Technicians (NREMTs) surveyed a national sample of EMTs as part of the ongoing
Longitudinal Emergency Medical Technician Attributes and Demographics Study (LEADS) Project. This paper reports on previously unpublished data collected as part of the LEADS project.

This study investigated how patient initiated workplace aggression was related to the characteristics of nationally registered EMTs. Specifically, it examined whether ever (1) being cursed or being threatened; (2) being punched, being slapped, or being scratched; (3) being spat upon; (4) being stabbed or experiencing a stabbing attempt; and (5) being shot or experiencing a shooting attempt were associated with provider demographic and occupational factors. It also investigated the availability of certain violence related resources, specifically, the ease of obtaining police assistance, EMS service provision of body armor, and EAP program access.

\section{Methods}

2.1. Study Design/Participant Selection. Data used for this research were obtained from the 2000 LEADS study. The LEADS I project was a 10-year project that began in 1998 and was created to describe the individuals providing EMS throughout the US. This study was conducted annually by the NREMT, a national EMS certification agency. A complete description of the study design for this project was previously published [17]. The LEADS I project included a core survey which was developed by a panel of EMS experts and administered to study participants annually. The core items were supplemented with different sets of questions, each year, focusing on specific issues relevant to the industry. In 2000, the survey was mailed to the sampled EMT-Basics and EMT-paramedics, along with a postage-paid return envelope and a letter that outlined the goals of the project and provided assurances of confidentiality. In addition, to motivate respondents, two round-trip airline tickets to any location within the continental United States were offered to a randomly selected participant. Survey questions were pilot tested using cognitive debriefings on a small sample of nationally registered EMS professionals. The year 2000 was the only year when workplace violence was the topic of investigation and subsequent years have focused on other issues relevant to EMS education or health and safety.

The sample population for the LEADS I project was a random stratified sample of nationally registered Emergency Medical Technician, Basics and Emergency Medical Technician, Paramedics. The sample was stratified by ethnicity (White versus non-White), years of EMS experience (less than 2 years versus 2 years or more), and level of EMS practice (EMT-Basic or EMT-paramedic). Each individual was assigned a weight based on the stratum from which they were selected. These weights were adjusted for stratum response rates. Completed questionnaires were processed with an optical reader and used to create an analytic data file. Completion did not influence national registration status. The American Institutes for Research's Institutional Review Board reviewed and approved this project. 


\subsection{Variable Description}

2.2.1. Dependent Variables. Respondents were asked to indicate if they or their partner had ever been assaulted by a patient. The primary measures of interest were "punching, slapping, or scratching"; "spitting"; "cursing or making threats"; "stabbing or stabbing attempts"; and "shooting or shooting attempts". Since "stabbing or stabbing attempts" and "shooting or shooting attempts" were rare events, these two measures were combined into a new category called "serious violence." This analysis was not able to differentiate between participants who had directly experienced from those who had a partner that experienced violence from a patient.

Respondents were also asked to indicate "How easy is it to get police assistance, when needed, when you are providing patient services?" with the five response categories: "Very easy," "Easy," "Somewhat difficult," "Difficult," and "Very difficult." For multivariate regression modeling, these responses were dichotomized into "Very easy" and "Not very easy" categories. Access to an EAP was measured using responses to the question "Does your EMS service have an employee assistance program that provides counseling or other services for stress, substance abuse, or other employee problems?" Response options were "Yes," "No," and "Do not know." For multivariate regression modeling, these responses were dichotomized into "Yes" and "No" categories. The "No" category included "Do not know" responses because it was hypothesized that the presence of an EAP would only have an impact if the employee was aware of the EAP's existence.

Self-assessment of restraint training was measured using responses to the question "Are you adequately trained to restrain a violent patient?" Response options were "Yes" and "No." Access to body armor was measured using responses to the question "Does your EMS service provide body armor to EMTs who wish to use it?" Response options were "Yes," "No," and "Do not know." Body armor use was measured using responses to the question "How often do you use body armor?" Response options were "Always," "Usually," "Sometimes," "Rarely," and "Never."

2.2.2. Independent Variables. The independent variables were chosen based on their probable association with workplace violence. Since this analysis used data from a survey developed to describe general demographics and characteristics of EMS professionals, analysis was limited to variables included on the questionnaire.

Service type was categorized as fire-based or non-firebased (county or municipal-based, hospital based, volunteer rescue, or other). Previous research was used as a guide [18] to collapse 8 categories of work community size into either urban (mid-sized city (less than 500,000 people), suburb/fringe of a mid-sized city, large city $(500,000$ or more people), or suburb/fringe of a large city) or nonurban (rural area (less than 2,500 people), small town (2,500-24,999 people), medium-sized town (25,000-74,999 people), or large town (75,000-149,999 people)) categories.

Independent variables were classified as demographic or work-related. Demographic variables included (1) marital status; (2) years of EMS service ( $<5$ years, 5-10 years, and $>10$ years); (3) gender; (4) community size where participant does most of their EMT work (urban, nonurban); and (5) current EMT level of practice (basic or paramedic). Specific variables related to a participant's EMS work were also analyzed. These variables included (1) type of EMS organization (fire-based or non-fire-based); (2) type of EMS work (all calls emergency related or not all emergency calls); (3) the perception of being adequately trained to restrain a violent patient (yes or no); and (4) if the respondent had ever used body armor (yes or no).

2.3. Data Analysis. EMS professionals who indicated that they were on active duty in the military and EMTs who reported that they were not currently practicing were excluded from analysis.

Relationships between the independent variables and the different types of violence were assessed by calculating and comparing the weighted proportions of respondents reporting each type of violence, through the use of chisquare tests (SAS Version 9.3, PROC SURVEYFREQ). Similar analyses were conducted to assess first-order relationships between type of service, adequate training to restrain violent patients, and the use of body armor and each type of violence.

A multivariable logistic regression model was fit to the dichotomous outcome of reporting the experience of each type of patient initiated violence in order to identify variables significantly associated with these. The independent variables included in the model were level of EMT practice, gender, community size, type of service, type of EMS work, and years of experience. Experience was treated as a continuous variable, using the midpoint of the experience categories. Data processing and tests of statistical significance were conducted using SAS Version 9.3, PROC SURVEYLOGISTIC (SAS Institute, Inc., Cary, NC). A second model, measuring the impacts of gender, community size, practice level, type of service, type of work, and experience with the presence of an EAP, was also developed and tested. A final model, measuring the impacts of gender, community size, practice level, type of service, type of work, and experience with the ease of getting police assistance, was also developed and tested. These data were also weighted.

\section{Results}

In 2000, 4,670 EMS professionals were asked to complete a LEADS survey. A total of 1,900 surveys were returned for an overall response rate of $41 \%$.

The distribution of survey respondent and employer characteristics are displayed in Table 1. Most (64\%) of the respondents were male. EMT-paramedics composed onethird $(33 \%)$ of the respondents. A little more than onehalf $(57 \%)$ of the respondents had worked in EMS for less than 5 years and $21 \%$ had worked for more than 10 years. Approximately half of the respondents (52\%) worked for services that provided only emergency patient transports. More than three-quarters of the respondents reported working in communities with populations less than 149,999 people. Half of the respondents (50\%) felt adequately trained to restrain 
TABLE 1: Descriptive statistics for EMT demographic and workforce safety questions.

\begin{tabular}{|c|c|}
\hline & Percent \\
\hline \multicolumn{2}{|c|}{ Level of EMT practice $(n=1,660)$} \\
\hline NREMT-basic & $67.0 \%$ \\
\hline NREMT-paramedic & $33.0 \%$ \\
\hline \multicolumn{2}{|l|}{ EMT gender $(n=1,646)$} \\
\hline Male & $64.4 \%$ \\
\hline Female & $35.6 \%$ \\
\hline \multicolumn{2}{|l|}{ EMT marital status $(n=1,591)$} \\
\hline Married or cohabiting & $71.3 \%$ \\
\hline Divorced or separated & $25.3 \%$ \\
\hline Never married/widowed & $3.4 \%$ \\
\hline \multicolumn{2}{|c|}{ EMT years of experience $(n=1,439)$} \\
\hline$<5$ years & $56.8 \%$ \\
\hline $5-10$ years & $22.2 \%$ \\
\hline$>10$ years & $21.0 \%$ \\
\hline \multicolumn{2}{|l|}{ Community size $(n=1,563)$} \\
\hline Urban $(>150,000)$ & $22.1 \%$ \\
\hline Other $(\leq 149,999)$ & $77.9 \%$ \\
\hline \multicolumn{2}{|l|}{ Type of EMS work $(n=1,575)$} \\
\hline All emergency & $51.8 \%$ \\
\hline Not all emergency & $48.2 \%$ \\
\hline \multicolumn{2}{|l|}{ Type of service $(n=1,389)$} \\
\hline Fire-based & $38.6 \%$ \\
\hline Non-fire-based & $61.4 \%$ \\
\hline \multicolumn{2}{|c|}{$\begin{array}{l}\text { Adequately trained to restrain a violent patient }(n= \\
1,628)\end{array}$} \\
\hline Yes & $49.6 \%$ \\
\hline No & $50.4 \%$ \\
\hline \multicolumn{2}{|l|}{ Service has an EAP $(n=1,621)$} \\
\hline Yes & $15.6 \%$ \\
\hline No & $71.3 \%$ \\
\hline Do not know & $13.1 \%$ \\
\hline \multicolumn{2}{|c|}{ Service provides body armor $(n=1,622)$} \\
\hline Yes & $75.5 \%$ \\
\hline No & $9.5 \%$ \\
\hline Do not know & $15.0 \%$ \\
\hline \multicolumn{2}{|c|}{ EMT wear body armor $(n=1,625)$} \\
\hline Yes & $92.5 \%$ \\
\hline No & $7.5 \%$ \\
\hline \multicolumn{2}{|c|}{ How often body armor is used $(n=1,625)$} \\
\hline Always & $2.1 \%$ \\
\hline Usually & $0.9 \%$ \\
\hline Sometimes & $3.6 \%$ \\
\hline Rarely & $5.9 \%$ \\
\hline Never & $87.5 \%$ \\
\hline \multicolumn{2}{|c|}{ Ease of getting police assistance $(n=1,618)$} \\
\hline Very easy & $43.4 \%$ \\
\hline Easy & $42.8 \%$ \\
\hline Somewhat difficult & $11.3 \%$ \\
\hline Difficult & $1.5 \%$ \\
\hline Very difficult & $1.0 \%$ \\
\hline
\end{tabular}

a violent patient. Over two-thirds (71\%) of EMTs reported their service had an EAP program. Over three-quarters (76\%) worked for services that did not provide body armor, and the vast majority $(88 \%)$ of all the respondents never used body armor. Additionally, less than one-sixth (14\%) experienced difficulty in obtaining police assistance while on a call.

Most of the respondents $(67 \%, 95 \% \mathrm{CI}=63.7 \%-69.5 \%)$ reported that either they or their partner had ever been cursed or threatened by a patient; $45 \%$ (95\% CI $=42.4 \%-$ $48.3 \%$ ) had ever been punched, slapped, or scratched and $41 \%$ $(95 \%$ CI $=37.9 \%-43.7 \%)$ were ever spat upon. Four percent (95\% CI $=2.8 \%-5.0 \%)$ of the respondents reported that they or their partner had even been stabbed or involved in an attempted stabbing, and $4 \%(95 \% \mathrm{CI}=2.5 \%-4.8 \%)$ reported ever being shot or involved in a shooting attempt by a patient.

As shown in Table 2(a), EMT-Basics or their partners were significantly less likely to have been cursed or threatened than EMT-Basics $(\mathrm{OR}=0.10, p<0.0001)$. Similarly, females or their partners were less likely to have experienced curses or threats than males ( $\mathrm{OR}=0.57, p<0.0001)$; less experienced EMTs or their partners were significantly less likely to have been cursed or threatened than those with more than 10-year experience ( $\mathrm{OR}=0.25, p<0.0001$ ); EMTs or their partners that worked for a fire-based service were significantly more likely to have been cursed or threatened than those that worked for a non-fire-based service $(\mathrm{OR}=$ 1.40, $p<0.05$ ); and EMTs or their partners who practiced in a nonurban environment were significantly less likely to have been cursed or threatened than those who practiced in an urban environment $(\mathrm{OR}=0.39, p<0.0001)$.

Similar, but not identical, associations between characteristics of the nearly half (45\%) of the EMS personnel and their partners who had ever been punched, slapped, or scratched by a patient were noted. EMT-Basics or their partners were significantly less likely to have been punched, slapped, or scratched than paramedics (OR $=0.20, p<0.0001)$; females or their partners were less likely to have been punched, slapped, or scratched than males (OR $=0.68, p<0.01)$; less experienced EMTs or their partners were significantly less likely to have been punched, slapped, or scratched than those with more than 10 -year experience $(\mathrm{OR}=0.30, p<$ $0.0001)$; EMTs or their partners who worked for a service that provided only emergency transports were significantly less likely to have been punched, slapped, or scratched than those who worked for agencies that provided nonemergency transports $(\mathrm{OR}=0.65, p<0.01)$; and EMTs or their partners who practiced in a nonurban environment were significantly less likely to have been punched, slapped, or scratched than those who practiced in an urban environment $(\mathrm{OR}=0.51$, $p<0.0001)$.

EMT-Basics or their partners were significantly less likely to have been spat upon than paramedics $(\mathrm{OR}=0.18, p<$ $0.0001)$; females or their partners were less likely to have been spat upon than males $(\mathrm{OR}=0.76, p<0.05)$; less experienced EMTs or their partners were significantly less likely to have been spat upon than those with more than 10 -year experience $(\mathrm{OR}=0.22, p<0.0001)$; EMTs or their partners that worked for a fire-based service were significantly more likely to have been spat upon than those that worked for a non-fire-based service $(\mathrm{OR}=1.43, p<0.05)$; and EMTs or their partners who practiced in an nonurban environment were significantly less 
TABLE 2: (a) Characteristics of EMTs experiencing different types of violence. (b) Characteristics of EMTs experiencing different types of violence.

(a)

\begin{tabular}{|c|c|c|c|c|c|c|}
\hline \multirow{2}{*}{ Variable } & \multicolumn{2}{|c|}{ Ever cursed/threatened } & \multicolumn{2}{|c|}{ Ever punched/slapped/scratched } & \multicolumn{2}{|c|}{ Ever been spat upon } \\
\hline & $\%$ & OR $(95 \% \mathrm{CI})$ & $\%$ & OR $(95 \% \mathrm{CI})$ & $\%$ & OR $(95 \% \mathrm{CI})$ \\
\hline \multicolumn{7}{|l|}{ Level of EMT practice } \\
\hline Paramedic $(n=699)$ & 92.0 & 1.00 & 70.4 & 1.00 & 67.4 & 1.00 \\
\hline EMT-basic $(n=472)$ & 53.7 & $0.10(0.07-0.15)^{* * * *}$ & 32.7 & $0.20(0.16-0.27)^{* * * *}$ & 27.4 & $0.18(0.14-0.24)^{* * * *}$ \\
\hline \multicolumn{7}{|l|}{ EMT gender } \\
\hline Male $(n=831)$ & 71.2 & 1.00 & 48.6 & 1.00 & 43.1 & 1.00 \\
\hline Female $(n=340)$ & 58.3 & $0.57(0.43-0.75)^{* * * *}$ & 39.3 & $0.68(0.52-0.90)^{* *}$ & 36.4 & $0.76(0.58-1.00)^{*}$ \\
\hline \multicolumn{7}{|l|}{ EMT experience } \\
\hline$<5$ years $(n=577)$ & 55.8 & $0.25(0.15-0.39)^{* * * *}$ & 34.6 & $0.30(0.21-0.44)^{* * * *}$ & 28.4 & $0.22(0.15-0.32)^{* * * *}$ \\
\hline $5-10$ years $(n=356)$ & 80.4 & $0.80(0.45-1.41)$ & 56.7 & $0.75(0.50-1.13)$ & 53.7 & $0.64(0.42-0.97)$ \\
\hline$>10$ years $(n=237)$ & 83.7 & 1.00 & 63.6 & 1.00 & 64.4 & 1.00 \\
\hline \multicolumn{7}{|l|}{ Type of service } \\
\hline $\begin{array}{l}\text { Non-fire-based } \\
(n=685)\end{array}$ & 63.8 & 1.00 & 44.6 & 1.00 & 37.0 & 1.00 \\
\hline Fire-based $(n=486)$ & 71.1 & $1.40(1.03-1.91)^{*}$ & 44.1 & $0.98(0.74-1.30)$ & 45.6 & $1.43(1.08-1.90)^{*}$ \\
\hline \multicolumn{7}{|l|}{ Community size } \\
\hline $\begin{array}{l}\text { Urban }(>150,000) \\
(n=814)\end{array}$ & 81.4 & 1.00 & 58.4 & 1.00 & 58.2 & 1.00 \\
\hline $\begin{array}{l}\text { Other }(\leq 149,999) \\
(n=357)\end{array}$ & 63.1 & $0.39(0.27-0.57)^{* * * *}$ & 41.8 & $0.51(0.35-0.69)^{* * * *}$ & 36.5 & $0.41(0.31-0.56)^{* * * *}$ \\
\hline \multicolumn{7}{|l|}{ Type of EMS work } \\
\hline $\begin{array}{l}\text { All emergency related } \\
(n=633)\end{array}$ & 65.7 & $0.81(0.61-1.08)$ & 40.9 & $0.65(0.50-0.84)^{* *}$ & 39.3 & $0.83(0.64-1.07)$ \\
\hline $\begin{array}{l}\text { Not all emergency } \\
(n=539)\end{array}$ & 70.3 & 1.00 & 51.5 & 1.00 & 44.0 & 1.00 \\
\hline \multicolumn{7}{|l|}{ EMT marital status } \\
\hline $\begin{array}{l}\text { Married/cohabiting } \\
(n=580)\end{array}$ & 67.2 & $1.36(0.66-2.83)$ & 45.1 & $0.79(0.40-1.58)$ & 42.0 & $0.78(0.39-1.56)$ \\
\hline $\begin{array}{l}\text { Divorced/separated } \\
(n=246)\end{array}$ & 67.9 & $1.41(0.66-3.03)$ & 46.7 & $0.85(0.41-1.75)$ & 37.9 & $0.66(0.32-1.36)$ \\
\hline $\begin{array}{l}\text { Never married/widowed } \\
(n=34)\end{array}$ & 60.1 & 1.00 & 50.8 & 1.00 & 48.1 & 1.00 \\
\hline \multicolumn{7}{|l|}{$\begin{array}{l}\text { EMT adequately trained to } \\
\text { restrain violent patients }\end{array}$} \\
\hline Yes $(n=607)$ & 69.6 & 1.00 & 48.4 & 1.00 & 43.5 & 1.00 \\
\hline No $(n=564)$ & 63.7 & $0.77(0.58-1.01)$ & 42.3 & $0.78(0.61-1.01)$ & 38.0 & $0.80(0.62-1.03)$ \\
\hline \multicolumn{7}{|c|}{ Body armor ever used by EMT } \\
\hline Yes $(n=169)$ & 74.1 & 1.00 & 52.8 & 1.00 & 49.9 & 1.00 \\
\hline No $(n=1,002)$ & 65.5 & $0.66(0.43-1.03)$ & 44.3 & $0.71(0.49-1.03)$ & 39.5 & $0.66(0.45-0.95)^{*}$ \\
\hline
\end{tabular}

${ }^{*} p<0.05 ;{ }^{* *} p<0.01 ;{ }^{* * * *} p<0.0001$.

Note: $n$ 's are the minimum cell size for the indicated row.

(b)

\begin{tabular}{lcccc}
\hline Variable & \multicolumn{2}{c}{$\begin{array}{c}\text { Ever stabbed/stabbing attempt } \\
\text { OR }(95 \% \mathrm{CI})\end{array}$} & \multicolumn{2}{c}{ Ever shot/shooting attempt } \\
OR (95\% CI)
\end{tabular}


(b) Continued.

\begin{tabular}{|c|c|c|c|c|}
\hline \multirow{2}{*}{ Variable } & \multicolumn{2}{|c|}{ Ever stabbed/stabbing attempt } & \multicolumn{2}{|c|}{ Ever shot/shooting attempt } \\
\hline & $\%$ & OR (95\% CI) & $\%$ & OR $(95 \% \mathrm{CI})$ \\
\hline \multicolumn{5}{|l|}{ EMT experience } \\
\hline$<5$ years $(n=576)$ & 2.0 & $0.27(0.13-0.60)^{* *}$ & 2.0 & $0.23(0.09-0.55)^{* *}$ \\
\hline $5-10$ years $(n=354)$ & 4.7 & $0.66(0.31-1.41)$ & 3.9 & $0.46(0.20-1.07)$ \\
\hline$>10$ years $(n=235)$ & 7.0 & 1.00 & 8.1 & 1.00 \\
\hline \multicolumn{5}{|l|}{ Type of service } \\
\hline Non-Fire-based $(n=684)$ & 3.1 & 1.00 & 3.5 & 1.00 \\
\hline Fire-based $(n=482)$ & 4.2 & $1.39(0.73-2.63)$ & 3.6 & $1.05(0.51-2.18)$ \\
\hline \multicolumn{5}{|l|}{ Community size } \\
\hline $\begin{array}{l}\text { Urban }(>150,000) \\
(n=813)\end{array}$ & 9.4 & 1.00 & 7.9 & 1.00 \\
\hline $\begin{array}{l}\text { Other }(\leq 149,999) \\
(n=355)\end{array}$ & 2.4 & $0.24(0.13-0.43)^{* * * *}$ & 2.6 & $0.31(0.16-0.61)^{* * *}$ \\
\hline \multicolumn{5}{|l|}{ Type of EMS work } \\
\hline $\begin{array}{l}\text { All emergency related } \\
(n=629)\end{array}$ & 3.9 & $1.03(0.57-1.86)$ & 3.0 & $0.69(0.35-1.36)$ \\
\hline $\begin{array}{l}\text { Not all emergency } \\
(n=537)\end{array}$ & 3.8 & 1.00 & 4.4 & 1.00 \\
\hline \multicolumn{5}{|l|}{ EMT marital status } \\
\hline $\begin{array}{l}\text { Married/cohabiting } \\
(n=580)\end{array}$ & 3.9 & $0.21(0.08-0.53)^{*}$ & 3.2 & $0.40(0.10-1.71)$ \\
\hline $\begin{array}{l}\text { Divorced/separated } \\
(n=242)\end{array}$ & 2.3 & $0.12(0.04-0.40)^{* *}$ & 4.6 & $0.59(0.13-2.69)$ \\
\hline $\begin{array}{l}\text { Never married/widowed } \\
(n=34)\end{array}$ & 16.3 & 1.00 & 7.6 & 1.00 \\
\hline \multicolumn{5}{|c|}{$\begin{array}{l}\text { EMT adequately trained to restrain } \\
\text { violent patients }\end{array}$} \\
\hline Yes $(n=604)$ & 4.6 & 1.00 & 3.8 & 1.00 \\
\hline No $(n=562)$ & 3.2 & $0.69(0.38-1.24)$ & 3.6 & $0.95(0.49-1.82)$ \\
\hline \multicolumn{5}{|l|}{ Body armor ever used by EMT } \\
\hline Yes $(n=169)$ & 6.9 & 1.00 & 7.0 & 1.00 \\
\hline No $(n=997)$ & 3.5 & $0.48(0.25-0.93)^{*}$ & 3.2 & $0.44(0.21-0.91)^{*}$ \\
\hline
\end{tabular}

likely to have been spat upon than those who practiced in an urban environment $(\mathrm{OR}=0.41, p<0.0001)$.

EMT-Basics or their partners were significantly less likely to have ever been stabbed or experience a stabbing attempt than paramedics $(\mathrm{OR}=0.23, p<0.0001)$; females or their partners were less likely to have ever been stabbed or experience a stabbing attempt than males $(\mathrm{OR}=0.41, p<0.05)$; less experienced EMTs or their partners were significantly less likely to have ever been stabbed or experience a stabbing attempt than those with more than 10-year experience (OR $=0.27, p<0.01)$; and EMTs or their partners who practiced in a nonurban environment were significantly less likely to have ever been stabbed or experience a stabbing attempt than those who practiced in an urban environment $(\mathrm{OR}=0.24$, $p<0.0001)$.

EMT-Basics or their partners were significantly less likely to have ever been shot or experienced an attempted shooting than paramedics $(\mathrm{OR}=0.32, p<0.01)$; less experienced EMTs or their partners were significantly more likely to have ever been shot or experienced an attempted shooting than those with more than 10 -year experience $(\mathrm{OR}=0.23$, $p<0.01)$; and EMTs or their partners who practiced in an nonurban environment were significantly less likely to have ever been shot or experienced an attempted shooting than those who practiced in an urban environment $(\mathrm{OR}=0.31$, $p<0.001)$.

EMTs who had never been spat upon; had never been stabbed; or experienced a stabbing attempt and those who had never been shot or experienced a shooting attempt were all significantly less likely to wear body armor $(\mathrm{ORs}=0.66$, 0.48 , and 0.44 , resp., all $p<0.05$ ). There was a decreased likelihood for EMTs who were never cursed/threatened and those who were never punched/slapped/scratched to wear body armor, but these were only marginally significant (ORs $=0.66$ and $0.71, p=0.06$ and 0.07 , resp.).

Being adequately trained to restrain a violent patient was not significantly associated with the likelihood of any type of work-related violence. Marital status was only associated with the likelihood of ever being stabbed or experiencing an attempted stabbing, with individuals who were separated or 
divorced and those who were married or cohabiting being less likely to experience this form of violence more often than individuals who were never married or widowed (ORs $=0.21$ and $0.12, p<0.05$ ).

3.1. Multivariate Analyses. As previously indicated, exposure to violence was significantly associated with experience. Since experience is associated with level (i.e., paramedics, on average, have more experience than EMT-Basics) and since there are relationships between many of the other independent variables (i.e., paramedics are more likely to work in urban areas), multivariate analyses were conducted to control for these relationships. Results from the multivariate logistic models are presented in Table 3. The odds of being cursed/threatened were significantly higher for more experienced respondents $(\mathrm{OR}=1.08, p<0.0001)$ and significantly lower for respondents working in a nonurban environment $(\mathrm{OR}=0.53, p<0.05)$. They were also significantly lower for females (OR $=0.65, p<0.05)$ and lower for NREMTBasics than for paramedics (OR $=0.17, p<0.0001)$. The previously noted association between type of service and being cursed or threatened was not present when other demographic and workplace characteristics were controlled for in the multivariate analysis.

The odds of being spat upon were significantly lower for NREMT-Basics (OR $=0.30, p<0.0001)$ and for respondents working in a nonurban environment $(\mathrm{OR}=0.51, p<0.001)$ and significantly higher for more experienced respondents $(\mathrm{OR}=1.10, p<0.0001)$. Similarly the significant firstorder associations between gender and being spat upon and type of service and being spat upon was not significant after controlling for other characteristics.

The odds of being punched, slapped, or scratched were lower among NREMT-Basics ( $\mathrm{OR}=0.31, p<0.0001$ ), lower among individuals who had all emergency related calls (OR $=0.61, p<0.01$ ), lower among respondents working in a nonurban environment $(\mathrm{OR}=0.65, p<0.05)$, and higher among respondents with more years of experience compared to respective referent categories $(\mathrm{OR}=1.07, p<0.0001)$. The association between gender and being punched, slapped, or scratched was not significant in the multivariate analyses.

Controlling for demographic and workplace characteristics, the odds of being stabbed or being involved in a stabbing attempt were lower among females $(\mathrm{OR}=0.27$, $p<0.05)$, lower among respondents working in a nonurban environment $(\mathrm{OR}=0.21, p<0.0001)$, and higher among respondents with more years of experience compared to respective referent categories $(\mathrm{OR}=1.08, p<0.05)$. However, level of practice and the experience of either being stabbed or being involved in a stabbing attempt were no longer a significant predictor of this type of violence.

The odds of being shot or being involved in a shooting attempt were lower among individuals whose workload consisted of all emergency calls ( $\mathrm{OR}=0.42, p<0.05$ ), lower among respondents working in a nonurban environment (OR $=0.32, p<0.05$ ), and higher among respondents with more years of experience compared to respective referent categories $(\mathrm{OR}=1.11, p<0.01)$. The previously noted association between level of practice and the experience of being shot or being involved in a shooting attempt was not present when other characteristics were taken into account.

The odds of experiencing serious violence were lower among individuals whose EMS work only involved emergency calls $(\mathrm{OR}=0.42, p<0.01)$, lower among respondents working in a nonurban environment $(\mathrm{OR}=0.26, p<0.0001)$, and higher among respondents with more years of experience $(\mathrm{OR}=1.11, p<0.0001)$.

Respondents in nonurban areas were significantly more likely $(\mathrm{OR}=1.51, p<0.05)$ to report it was very easy to get police assistance when needed than respondents in urban areas $(p<0.05)$ (Table 4). Respondents working for services in nonurban areas were also significantly less likely to have an $\mathrm{EAP}(\mathrm{OR}=0.36, p<0.0001)$, while fire-based service employees were significantly more likely to have an EAP (OR $=2.25, p<0.001$ ).

\section{Discussion}

This study provides a national assessment of patient initiated workplace violence by nationally registered EMS professionals. It also describes the availability of certain violence related resources. Previous studies were administered in metropolitan areas and were mainly descriptive in nature, some of which either lacked certain demographic information $[2,4]$ or did not fully characterize the forms of violence encountered $[2,19]$. Additionally, with the exception of one study, researchers have opted to group violence into the larger categories of "verbal" and "physical" violence. The categorization and reporting of violence against EMS personnel have been proposed, by the American College of Emergency Physicians in 2013, as a possible item for consideration in the promotion of safety-related standards in EMS [5].

Authors have previously commented on the problem of quantifying the experience of violence given the difficulty in clearly defining what constitutes a verbal threat or abusive language within the context of each individual's tolerance and perceptions [4]. While differences in subjects' interpretations of the meaning of assault, violence, weapon, and so forth might have potentially biased the results of previous work, this current study defined the specific types of violence. Additionally, unless a standardized definition of assault is established in advance (as was done here), it is possible for the resultant data to include cases that were not in keeping with a study's original intent [20]. This improved characterization of the nature of prehospital violence provides a level of detail necessary to develop and institute appropriate preventive measures [21].

The current study included a substantially larger sample size than previous prehospital violence research and showed that patient initiated physical and nonphysical violence are frequently occurring work-place problems. Two-thirds (67\%) of the respondents or their partners had, at one time or another, been subjected to threats and/or physical violence from patients. While verbal abuse may be considered as less severe than physical assault, the consequences of verbal 


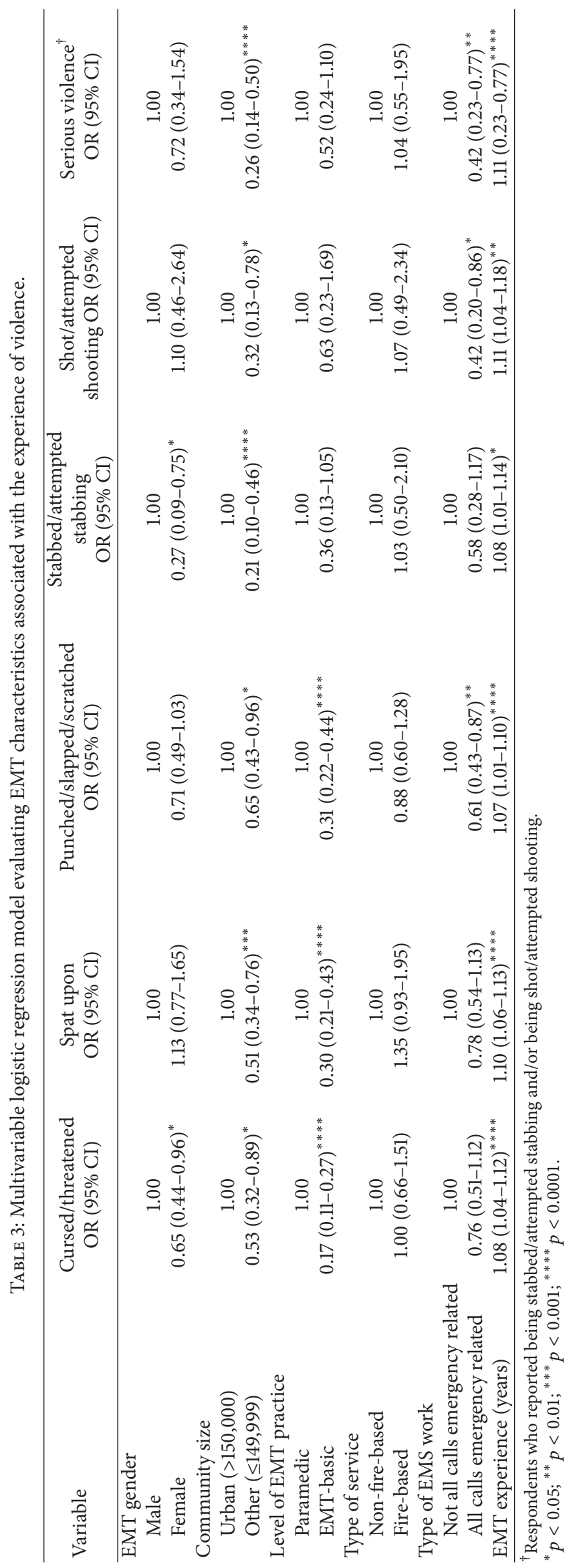


TABLE 4: Regression analyses evaluating EMT characteristics associated with ease of getting police assistance and presence of an EAP.

\begin{tabular}{|c|c|c|c|c|}
\hline \multirow{2}{*}{ Variable } & \multicolumn{2}{|c|}{ Very easy getting police assistance } & \multicolumn{2}{|c|}{ Presence of EAP } \\
\hline & $n$ & OR (95\% CI) & $n$ & OR $(95 \% \mathrm{CI})$ \\
\hline \multicolumn{5}{|l|}{ EMT gender } \\
\hline Male & 835 & 1.00 & 837 & 1.00 \\
\hline Female & 343 & $0.81(0.58-1.15)$ & 342 & $1.03(0.70-1.51)$ \\
\hline \multicolumn{5}{|l|}{ Community size } \\
\hline Urban $(>150,000)$ & 818 & 1.00 & 819 & 1.00 \\
\hline Other $(\leq 149,999)$ & 360 & $1.51(1.06-2.17)^{*}$ & 360 & $0.36(0.23-0.58)^{* * * *}$ \\
\hline \multicolumn{5}{|l|}{ Level of EMT practice } \\
\hline Paramedic & 703 & 1.00 & 704 & 1.00 \\
\hline EMT-basic & 475 & $1.02(0.73-1.43)$ & 475 & $0.78(0.53-1.16)$ \\
\hline \multicolumn{5}{|l|}{ Type of service } \\
\hline Non-fire-based & 689 & 1.00 & 690 & 1.00 \\
\hline Fire-based & 489 & $1.13(0.81-1.59)$ & 489 & $2.25(1.49-3.41)^{* * *}$ \\
\hline \multicolumn{5}{|l|}{ Type of EMS work } \\
\hline Not all calls emergency related & 542 & 1.00 & 544 & 1.00 \\
\hline All calls emergency related & 636 & $0.95(0.69-1.31)$ & 635 & $1.16(0.80-1.68)$ \\
\hline EMT experience (years) & 1,178 & $0.99(0.96-1.02)$ & 1,179 & $1.01(0.98-1.05)$ \\
\hline
\end{tabular}

${ }^{*} p<0.05 ;{ }^{* * *} p<0.001 ;{ }^{* * * *} p<0.0001$.

abuse should not be discounted. Other researchers have shown that individuals who experience verbal abuse are more likely to report poor general health $[22,23]$, as well as work-related injury and illness [6]. In some instances, providers had been spat upon, which may be perceived as a deadly threat given the risks of being infected [24]. The National Association of EMS Physicians (NAEMSP) recommends against placing anything over the face, head, or neck of a patient but advises that personnel dealing with a spitting patient may consider the use of a loosely placed surgical mask [25]. It is important to consider that the violence encountered by EMTs is likely to be higher than reported here, as this study investigated specific forms of violence initiated by patients, which excluded violence from family members and bystanders. The finding that $67 \%$ of respondents report experiencing workplace violence is similar to previously conducted research. Pozzi found that ninety percent of the EMS personnel from the Albuquerque Fire Department had experienced an assault or violent action directed toward them during their career [4]. Rahmani et al. studied the experience of workplace violence among Iran EMTs and found that $75 \%$ had experienced at least one form of workplace violence in the 12 months preceding the survey [26].

Here, experienced providers were more likely to report the occurrence of each violence type. Providers with 11 or more years of experience reported the highest levels of both physical and nonphysical violence. The observed association between years of provider experience and occurrence of violence is most likely a result of a longer accumulated time spent in direct patient contact, which increases the probability of encountering a violent patient. This is consistent with research from other areas of health care showing that occupational violence is common in professions involving substantial face-to-face communication with patients [27]. Additionally, Magnavita and Heponiemi found that health care workers in the Accident and Emergency Department of an Italian Public Health Care Facility were at a significantly higher risk of violence $(\mathrm{OR}=5.1,95 \% \mathrm{CI}=2.1-12.4$ for physical aggression, $\mathrm{OR}=7.6,95 \% \mathrm{CI}=3.2-18.2$ for threats) than health care workers engaged in business services (radiology, laboratories, and offices) [28].

A similar relationship was noted for level of practice, with EMT-paramedics reporting a higher rate of each type of violence than EMT-basics. These results were confirmed by multivariate analyses for all types of nonserious violence, controlling for experience (and other factors). EMTparamedics generally respond to more calls in a typical week (18.4 calls versus 4.2 calls for EMT-basics) [29], which may further explain the contribution of practice level to the experience of violence among EMTs. Additionally, EMTparamedics treat more severely injured patients $[30,31]$ and have the opportunity to support law enforcement personnel during dangerous deployments such as hostage situations and drug raids [32]. These situations may also increase the likelihood of EMT-paramedics experiencing violence. Similar patterns of workplace violence among more experienced personnel can be seen in other health careers. A retrospective survey comparing the experience of nurses and nursing students found that the adjusted odds ratios for physical assaults $(\mathrm{OR}=2.89 ; 95 \% \mathrm{CI}=1.35-6.18)$ and threats $(\mathrm{OR}=$ $2.84 ; 95 \% \mathrm{CI}=1.39-5.79)$ were significantly higher among nurses than among nursing students [33].

Prehospital providers who practiced in areas with populations exceeding 149,999 had a significantly greater likelihood of all types of violence than providers that practiced in less populated areas. The greater likelihood of each type of assault in more populated environments may be due to 
disproportionately higher rates of certain types of violence in urban areas, such as domestic violence and firearm homicide $[34,35]$. Overall, researchers have found that higher rates of violent crime are positively correlated with population size. Population size itself acts as a proxy aggregate variable that denotes a set of diverse socioeconomic mechanisms derived from the colocation and intense interaction of people [36].

Law enforcement personnel are present in 63\% [19], 82\% [37] of violent calls, of which officers arrived before EMS 70\% of the time [37]. Furthermore, 97\% of providers had called upon law enforcement to help manage a violent patient [37]. EMS providers need the ability to obtain police assistance easily and quickly, as violence may suddenly arise at any time during a call. Here, $13.7 \%$ of the nationally registered EMTs experienced some degree of difficulty in obtaining police assistance. Areas with a known difficulty for EMS providers to obtain police assistance may wish to consider the simultaneous dispatching of police personnel for those calls involving high-risk situations (e.g., suicide, homicide, domestic violence, intoxication, and psychiatric illness) or to addresses or areas previously associated with violence. The NAEMSP recommends that EMS personnel assure that law enforcement secures the scene prior to entry, if a patient or individual is known to be violent [25].

While the issue of weapons in the prehospital setting has not been clearly understood, there is some evidence to suggest that patients with weapons may be a common problem for EMS personnel. For example, a survey of providers from the Boston and Los Angeles metropolitan areas found that $62 \%$ of the providers who routinely searched their patients had found weapons. In a review of the narratives from 4,200 ambulance reports, Tintinalli and McCoy found that $12 \%$ of violent patients possessed weapons [37]. The results confirm the statements of other authors, who have commented that some EMS agencies have purchased body armor for their personnel [20]. Overall, 9.5\% of the nationally registered EMTs belonged to a service that provided body armor. Additionally, $14.0 \%$ of the EMTs that experienced serious violence belonged to a service that provided body armor (data not shown). Body armor was more likely to be used by personnel who had been assaulted (in all 5 categories), and significantly so for being shot or involved in an attempted shooting, or being stabbed or involved in a stabbing attempt, and being spat upon. It appears that being subjected to serious violence increases the likelihood of the use of body armor. Further studies are needed to determine the efficacy of body armor in reducing the severity of injuries from violence, as well as determining if the presence of body armor influences the risk taking behavior of EMS personnel. This is especially important given recent stakeholder recommendations that bulletproof vests be provided to EMS personnel [38].

The psychological impact of assaults on EMS providers is poorly understood, but evidence from the ED has shown that violence, or the threat of violence, can impact both the victims and their colleagues. Fernandes et al. found that ED employees who had either witnessed or experienced a violent incident reported impaired job performance $(48 \%$ for either the rest of the shift or the remainder of the week and $19 \%$ for an even longer period). Additionally, $67 \%$ of the respondents who no longer worked in the ED stated that violence was a contributing factor in their decision to leave the job [39]. Furthermore, a 2011 study found that nurses who had experienced violence were more likely to report poor health, as well as work related injury and illness [6]. Additional research suggests a bidirectional relationship between violence and work-related stress. A study of health care workers from a public health authority in Rome revealed that job strain and lack of social support were predictors of the occurrence of nonphysical aggression during the subsequent year [40]. In 2000, most EMTs (71\%) reported that their service had an EAP program, whereas $16 \%$ reported that their service did not have an EAP program and 13\% did not know if their service had an EAP program. While the number of providers reporting access to an EAP program may be encouraging, potential areas for improvement where EMS services might focus attention were also identified. Thirteen percent of the respondents were unaware if their service provided an EAP program. In addition to making more employees aware of available assistance, generally increasing EAP promotional messages and raising program visibility through worksite activities may also have a positive effect on utilization rates by workers [41]. Given previous findings that ED personnel were more likely to seek support from colleagues rather than an official debriefing [39], determining the degree to which EMS personnel use EAP programs is an area that clearly deserves further study.

Identifying the work-life characteristics associated with patient initiated violence among EMS professionals is just one step in attempting to protect provider safety, health, and well-being. The next step in this effort to understand work related violence among EMTs should be a followup study with the LEADS cohort. Resources have been identified to support this effort. The experience of prehospital violence is an area of concern. It is not unreasonable to believe that these factors are associated with EMT retention and attrition. Additional longitudinal EMT information on workplace violence is anticipated to determine the extent to which workplace violence is a factor in EMT retention.

Limitations. There are some limitations to this study. The $41 \%$ survey response rate, while comparable to the 32 to $78 \%$ range of response rates for the health care provider population [42] and other surveys on violence [43], may have introduced the potential for nonresponse bias in the current study. However, a high level of survey responder versus nonresponder demographic similarity has been noted in previous LEADS cohort analyses [17, 29]. While policies and practices may have changed substantially in the years since 2000, recent data suggests the prevalence of patient directed violence remains a significant concern for EMS [44]. Because providers were asked about the lifetime experience of violence, the annual prevalence of aggression could not be estimated. Additionally, respondents reported if they or their partner had ever been assaulted and the results cannot differentiate between participants who had directly experienced violence from those who had only witnessed it. While the authors are not aware of any major legislation or initiatives that have been implemented since the data 
was collected, there are other factors that might influence the prevalence of workplace violence. Lastly, the lifetime experience of violence may have been underreported as has been previously described [19].

Conclusion. While many nationally registered EMS professionals reported that they or their partners experienced different forms of patient initiated violence; this study revealed that violence varied across several important person and organizational factors. Providers who encounter violence and abuse, including, but not limited to, providers in urban areas, should be educated about the expected risks and follow-up plans implemented to support employees and prevent future occurrences. Further studies should be conducted to identify programs and systems that reduce the experience of violence and weapons and improve personal safety.

\section{Abbreviations List}

EAP: Employee assistance program

ED: $\quad$ Emergency Department

EMS: $\quad$ Emergency Medical Services

EMTs: Emergency Medical Technicians

LEADS: Longitudinal Emergency Medical

Technician Attributes and Demographics Study

NAEMSP: National Association of EMS Physicians

NREMT: National Registry of Emergency Medical Technicians.

\section{Conflict of Interests}

The authors declare that there is no conflict of interests regarding the publication of this paper.

\section{References}

[1] Bureau of Labor Statistics and US Department of Labor, Nonfatal Occupational Injuries and Illnesses Requiring Days Away from Work, Bureau of Labor Statistics, Washington, DC, USA, 2011, http://www.bls.gov/news.release/archives/osh2_11082012.pdf.

[2] J. T. Grange and S. W. Corbett, "Violence against emergency medical services personnel," Prehospital Emergency Care, vol. 6, no. 2, pp. 186-190, 2002.

[3] L. Jenkins, Violence in the Workplace: Risk Factors and Prevention Strategies, US Department of Health and Human Services, Centers for Disease Control and Prevention, National Institute for Occupational Safety and Health, 1996.

[4] C. Pozzi, "Exposure of prehospital providers to violence and abuse," Journal of Emergency Nursing, vol. 24, no. 4, pp. 320-323, 1998.

[5] American College of Emergency Physicians, Strategy for a National EMS Culture of Safety, 2013, http://www.emscultureofsafety.org/wp-content/uploads/2013/10/Strateg-for-a-NationalEMS-Culture-of-Safety-10-03-13.pdf.

[6] K. Fujishiro, G. C. Gee, and A. B. De Castro, "Associations of workplace aggression with work-related well-being among nurses in the philippines," American Journal of Public Health, vol. 101, no. 5, pp. 861-867, 2011.
[7] S. G. Gerberich, T. R. Church, P. M. McGovern et al., "An epidemiological study of the magnitude and consequences of work related violence: the Minnesota Nurses' Study," Occupational and Environmental Medicine, vol. 61, no. 6, pp. 495-503, 2004.

[8] M. Hokanson and B. Wirth, "The critical incident stress debriefing process for the Los Angeles County Fire Department: automatic and effective," International Journal of Emergency Mental Health, vol. 2, no. 4, pp. 249-257, 2000.

[9] Occupational Safety and Health Administration. US Department of Labor, "Guidelines for preventing workplace violence for healthcare and social service workers," OSHA 3148-01R, 2004, https://www.osha.gov/Publications/OSHA3148/osha3148 .html.

[10] P. D. Steele, "A history of job-based alcoholism programs: 19551972," Journal of Drug Issues, vol. 19, no. 4, pp. 511-532, 1989.

[11] H. M. Trice and J. Beyer, "Employee assistance programs: blending performance-oriented and humanitarian ideologies to assist emotionally disturbed employees," in Research in Community and Mental Health, J. R. Greenley, Ed., pp. 245-297, Jai Press, Greenwich, Conn, USA, 1984.

[12] P. M. Roman, "From employee alcoholism to employee assistance. Deemphases on prevention and alohol alcohol in workbased programs," Journal of Studies on Alcohol, vol. 42, no. 3, pp. 244-287, 1981.

[13] T. D. Hartwell, P. Steele, M. T. French, F. J. Potter, N. F. Rodman, and G. A. Zarkin, "Aiding troubled employees: the prevalence, cost, and characteristics of employee assistance programs in the United States," American Journal of Public Health, vol. 86, no. 6, pp. 804-808, 1996.

[14] M. A. Kendra, A. Weiker, S. Simon, A. Grant, and D. Shullick, "Safety concerns affecting delivery of home health care," Public Health Nursing, vol. 13, no. 2, pp. 83-89, 1996.

[15] J. H. Brice, R. G. Pirrallo, E. Racht, B. S. Zachariah, and J. Krohmer, "Management of the violent patient," Prehospital Emergency Care, vol. 7, no. 1, pp. 48-55, 2003.

[16] L. R. Becker and R. Spicer, Feasibility for an EMS Workforce Safety and Health Surveillance System, No. HS-810 756, National Highway Traffic Safety Administration, Washington, DC, USA, 2007, http://www.nhtsa.gov/DOT/NHTSA/Traffic\% 20Injury\%20Control/Articles/Associated\%20Files/EMSWorkforceFeasibility3.pdf.

[17] D. E. Dawson, W. E. Brown Jr., and T. S. Harwell, "Assessment of nationally registered emergency medical technician certification training in the United States: The LEADS Project. Longitudinal Emergency Medical Technician Attributes Demographic Study," Prehospital Emergency Care, vol. 7, no. 1, pp. 114-119, 2003.

[18] P. D. Patterson, C. G. Moore, N. D. Sanddal, G. Wingrove, and B. LaCroix, "Characterizing job satisfaction and intent to leave among nationally registered emergency medical technicians: an analysis of the 2005 LEADS survey," Journal of Allied Health, vol. 38, no. 3, pp. e84-e91, 2009.

[19] E. F. Mock, K. D. Wrenn, S. W. Wright, T. C. Eustis, and C. M. Slovis, "Prospective field study of violence in emergency medical services calls," Annals of Emergency Medicine, vol. 32, no. 1, pp. 33-36, 1998.

[20] C. C. Mechem, E. T. Dickinson, F. S. Shofer, and D. Jaslow, "Injuries from assaults on paramedics and firefighters in an urban emergency medical services system," Prehospital Emergency Care, vol. 6, no. 4, pp. 396-401, 2002. 
[21] S. W. Corbett, J. T. Grange, and T. L. Thomas, "Exposure of prehospital care providers to violence," Prehospital Emergency Care, vol. 2, no. 2, pp. 127-131, 1998.

[22] I. Niedhammer, J.-F. Chastang, and S. David, "Importance of psychosocial work factors on general health outcomes in the national French SUMER survey," Occupational Medicine, vol. 58, no. 1, pp. 15-24, 2008.

[23] M. Kivimäki, M. Elovainio, and J. Vahtera, "Workplace bullying and sickness absence in hospital staff," Occupational and Environmental Medicine, vol. 57, no. 10, pp. 656-660, 2000.

[24] K. Petzäll, J. Tällberg, T. Lundin, and B.-O. Suserud, “Threats and violence in the Swedish pre-hospital emergency care," International Emergency Nursing, vol. 19, no. 1, pp. 5-11, 2011.

[25] D. F. Kupas and G. C. Wydro, "Patient restraint in emergency medical services systems. (NAEMSP position statement)," Prehospital Emergency Care, vol. 6, no. 3, pp. 340-345, 2002.

[26] A. Rahmani, H. Hassankhani, J. Mills, and A. Dadashzadeh, "Exposure of Iranian emergency medical technicians to workplace violence: a cross-sectional analysis," Emergency Medicine Australasia, vol. 24, no. 1, pp. 105-110, 2012.

[27] C. Mayhew and D. Chappell, "An overview of occupational violence," Australian Nursing and Midwifery Journal, vol. 9, no. 7, pp. 34-35, 2002.

[28] N. Magnavita and T. Heponiemi, "Violence towards health care workers in a Public Health Care Facility in Italy: a repeated cross-sectional study," BMC Health Services Research, vol. 12, no. 1, pp. 108-117, 2012.

[29] W. E. Brown Jr., P. D. Dickison, W. J. A. Misselbeck, and R. Levine, "Longitudinal emergency medical technician attribute and demographic study (LEADS): an interim report," Prehospital Emergency Care, vol. 6, no. 4, pp. 433-439, 2002.

[30] A. Suruda, D. D. Vernon, J. Reading et al., "Pre-hospital emergency medical services: a population based study of pediatric utilization," Injury Prevention, vol. 5, no. 4, pp. 294-297, 1999.

[31] G. L. Foltin, S. Pon, M. Tunik et al., "Pediatric ambulance utilization in a large American city: a systems analysis approach," Pediatric Emergency Care, vol. 14, no. 4, pp. 254-258, 1998.

[32] R. Lucas, "Violence in the prehospital setting," Emergency Medicine Clinics of North America, vol. 17, no. 3, pp. 679-683, 1999.

[33] N. Magnavita and T. Heponiemi, "Workplace violence against nursing students and nurses: an Italian experience," Journal of Nursing Scholarship, vol. 43, no. 2, pp. 203-210, 2011.

[34] C. G. Moore, J. C. Probst, M. Tompkins, S. Cuffe, and A. B. Martin, "The prevalence of violent disagreements in US families: effects of residence, race/ethnicity, and parental stress," Pediatrics, vol. 119, supplement 1, pp. S68-S76, 2007.

[35] M. L. Nance, B. G. Carr, M. J. Kallan, C. C. Branas, and D. J. Wiebe, "Variation in pediatric and adolescent firearm mortality rates in rural and urban US counties," Pediatrics, vol. 125, no. 6, pp. 1112-1118, 2010.

[36] L. M. A. Bettencourt, J. Lobo, D. Strumsky, and G. B. West, "Urban scaling and its deviations: revealing the structure of wealth, innovation and crime across cities," PLOS ONE, vol. 5, no. 11, Article ID e13541, 2010.

[37] J. E. Tintinalli and M. McCoy, "Violent patients and the prehospital provider," Annals of Emergency Medicine, vol. 22, no. 8, pp. 1276-1279, 1993.

[38] Federal Interagency Committee on Emergency Medical Services National EMS and 9-1-1 Stakeholders Meeting Minutes, 2010.
[39] C. M. B. Fernandes, F. Bouthillette, J. M. Raboud et al., "Violence in the emergency department: a survey of health care workers," Canadian Medical Association Journal, vol. 161, no. 10, pp. 12451248, 1999.

[40] N. Magnavita, "Workplace violence and occupational stress in healthcare workers: a chicken-and-egg situation-results of a 6year follow-up study," Journal of Nursing Scholarship, vol. 46, no. 5, pp. 366-376, 2014.

[41] V. Azzone, B. McCann, E. L. Merrick, D. Hiatt, D. Hodgkin, and C. Horgan, "Workplace stress, organizational factors and EAP utilization," Journal of Workplace Behavioral Health, vol. 24, no. 3, pp. 344-356, 2009.

[42] D. A. Asch, M. K. Jedrziewski, and N. A. Christakis, "Response rates to mail surveys published in medical journals," Journal of Clinical Epidemiology, vol. 50, no. 10, pp. 1129-1136, 1997.

[43] M. J. Findorff, P. M. McGovern, M. Wall, S. G. Gerberich, and B. Alexander, "Risk factors for work related violence in a health care organization," Injury Prevention, vol. 10, no. 5, pp. 296-302, 2004.

[44] R. P. Crowe, J. J. Eggerichs, M. Gormley, T. Rodriguez, R. Levine, and M. A. Bentley, "A description of violence towards emergency medical services professionals," in Proceedings of the Annual Meeting of the National Association of Emergency Medical Service Physicians, Tucson, Ariz, USA, January 2014. 


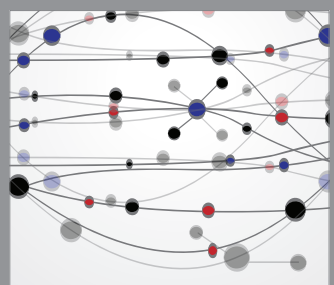

The Scientific World Journal
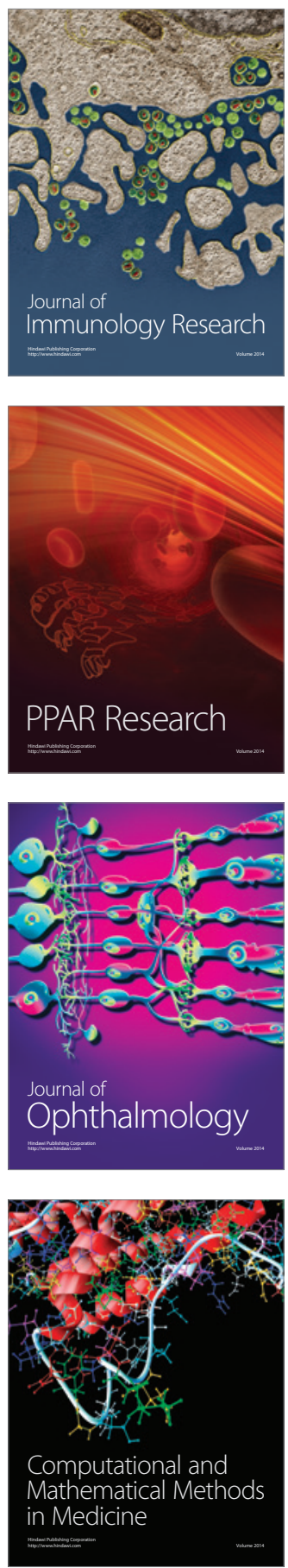

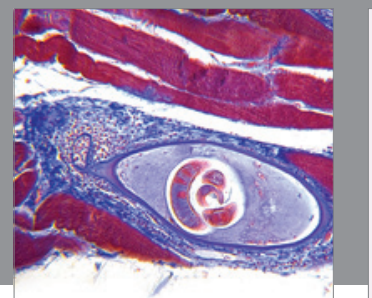

Gastroenterology

Research and Practice
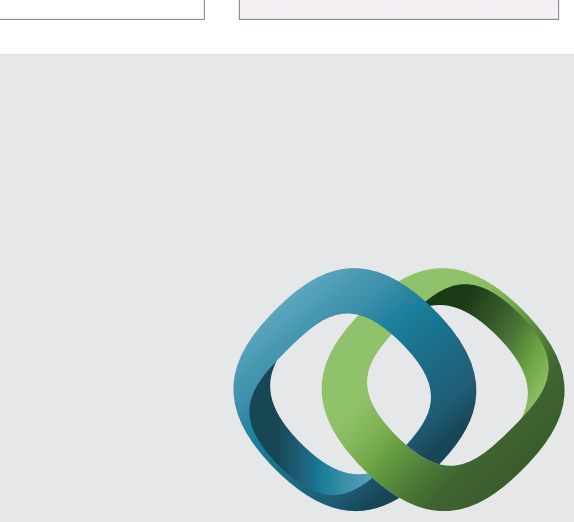

\section{Hindawi}

Submit your manuscripts at

http://www.hindawi.com
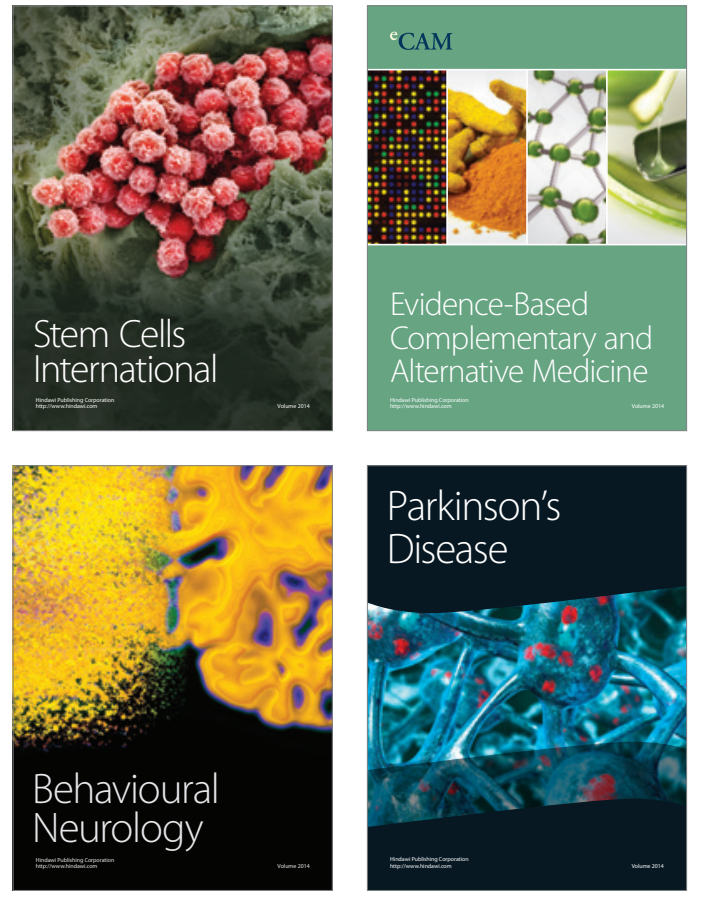
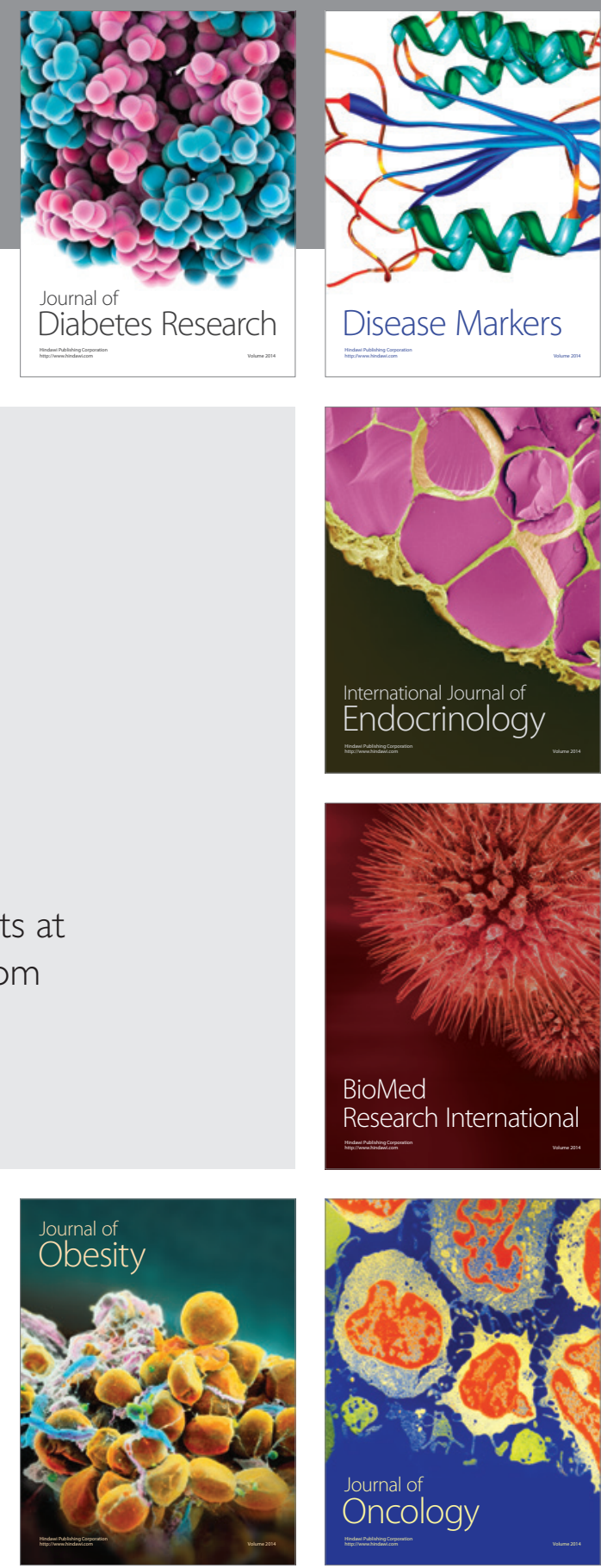

Disease Markers
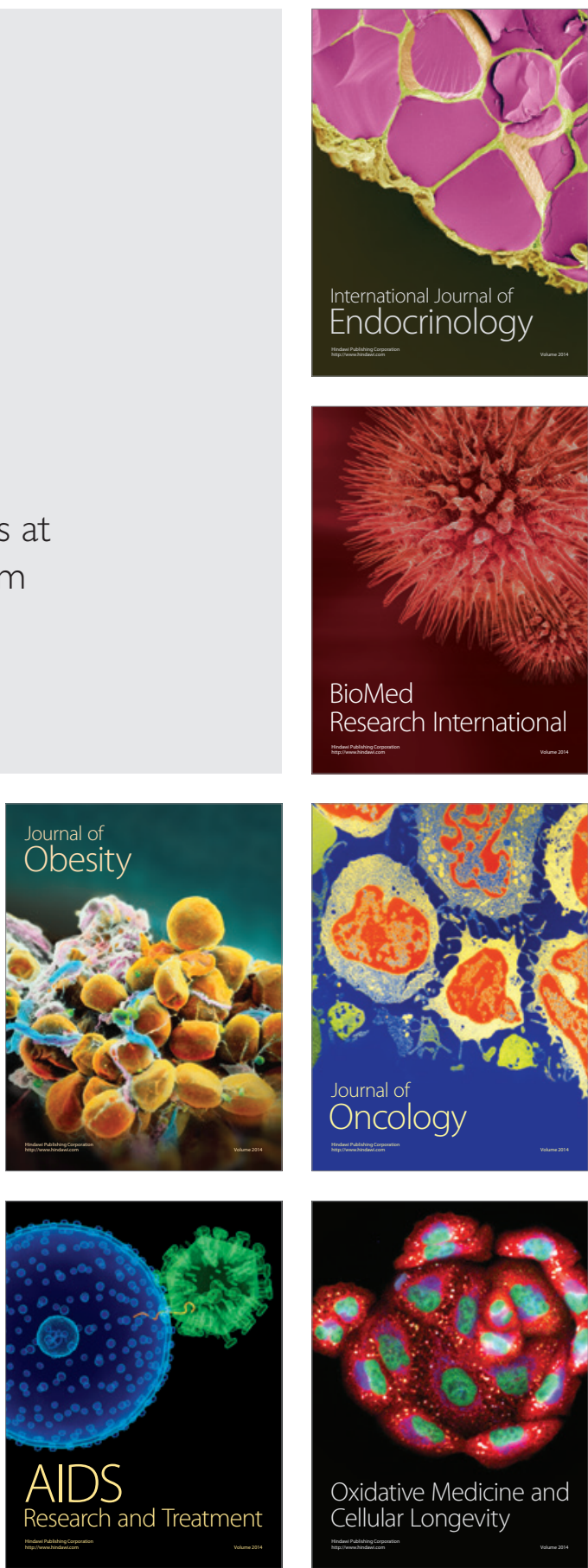